\title{
The effects of irrelevant speech on immediate free recall
}

\author{
PIERRE SALAMÉ \\ CNRS/INRS Laboratoire de Physiologie et Psychologie Environnementales, Strasbourg, France \\ and \\ ALAN BADDELEY \\ MRC Applied Psychology Unit, Cambridge, England
}

\begin{abstract}
Immediate ordered recall is strongly disrupted by concurrent irrelevant speech even when the speech is unfamiliar to the subject. This effect has been replicated in many experiments with immediate serial recall. In the present study, we examined the effect of speech on immediate free recall of lists of 16 words presented visually. No impairment in the speech condition was found in comparison with the control, but the same subjects showed a consistent impairment of immediate serial recall under speech in a separate experiment. It is concluded that irrelevant speech impairs immediate phonological memory but does not disrupt performance on either the long- or short-term components of the standard verbal free recall task.
\end{abstract}

It is now well established that immediate serial recall is consistently impaired when sequences of visual items are accompanied by irrelevant speech that the subject is instructed to ignore. This disruptive effect is not influenced by the intensity at which the speech is delivered (Colle, 1980; Salamé \& Baddeley, 1987), and the effect occurs even when the speech consists of foreign language unfamiliar to the subject (Baddeley \& Salamé, 1986; Colle \& Welsh, 1976; Salamé \& Baddeley, 1982, 1986, 1987).

Salamé and Baddeley (1982) explained the irrelevant speech effect in terms of the articulatory loop subsystem of the working memory framework (Baddeley \& Hitch, 1974). The articulatory loop is assumed to comprise two components, one for rehearsal and the other for storage. The loop accepts, however, only those items that are phonologically coded. Auditory material which already comprises a phonological code has direct access to the loop. Visual items enter the loop, providing they are recoded into a phonological form. The rehearsal component serves to recycle the phonological trace, which fades and becomes unretrievable within about 1.5-2 sec (Baddeley, Thomson, \& Buchanan, 1975). If articulation is suppressed, then the verbal items are not phonologically coded, their rehearsal is prevented, and they do not enter the phonological store; this leads to poor short-term recall. The irrelevant speech effect is assumed to occur because the phonological store accepts both the recoded visual and the irrelevant auditory items. This leads to a corruption of the phonological traces of the items to be recalled,

Thanks are due to Vera Dubois from the Institute of Dialectology of the Université des Sciences Humaines de Strasbourg, for her help in preparing the word lists, and to Ian Nimmo-Smith from the Applied Psychology Unit, for statistical advice. Correspondence should be addressed to Alan Baddeley, MRC Applied Psychology Unit, 15 Chaucer Road, Cambridge, CB2 2EF, England. producing impaired memory performance (Salamé \& Baddeley, 1986).

Although the working memory framework accounts for a range of tasks (see Baddeley, 1986), the effects of irrelevant speech have been observed principally on one basic task, namely, the immediate serial recall of sequences of digits or letters. This experimental paradigm requires the verbatim recall of the presented items in their correct order. The following experiment was aimed at examining the effects of irrelevant speech on the free recall of lists of common words presented visually, either in silence or in the presence of a continuous stream of foreign speech (Arabic) unfamiliar to the subjects. This task is commonly assumed to reflect two components. Performance on earlier items is often attributed to long-term memory, since it is not affected by the interpolation of a brief delay, is preserved in patients with defective shortterm memory and is impaired in amnesic patients (Baddeley \& Warrington, 1970). It is also sensitive to many variables that influence long-term learning, and it typically appears to reflect semantic encoding (Glanzer, 1972). In contrast, recall of the last few items-the recency effect-appears to reflect the operation of a separate system or process that is sensitive to delay and is preserved in amnesic patients (Baddeley \& Warrington, 1970; Glanzer, 1972).

One interpretation of the recency effect is that it reflects the output of a short-term store, a system that also underlies the performance of the digit span task. If so, one might expect irrelevant speech to disrupt the recency effect, just as it impairs memory span. Baddeley and Hitch (1974), however, have suggested that recency and span do not represent the operation of a common system, showing that recency is not disrupted by a concurrent digit span task. On this basis, one might expect no effect of irrelevant speech on recency. 
A second question concerns the influence of irrelevant speech on the long-term component of free recall. Richardson and Baddeley (1975) observed an effect of articulatory suppression on the long-term, but not the recency, component of free recall. This suggests that the articulatory loop may be used in the free recall task, and that there may be an effect of irrelevant speech on earlier items, but not on recency. We therefore decided to investigate the effect of irrelevant speech on immediate free recall.

\section{METHOD}

\section{Material and Design}

The task involved the free recall of lists of 16 two-syllable words. They were all common nouns, their frequencies ranging between 14 and 712 on the Juilland, Brodin, and Davidovitch (1970) count. Four lists served for the pretest, and a further eight lists were used for the test session. Mean frequency was balanced across lists, with each list comprising equal numbers of concrete and abstract nouns randomly distributed across serial positions.

Following a visual warning signal consisting of a $3 \times 2 \mathrm{~cm}$ rectangle that appeared for $2 \mathrm{sec}$, each word of a list was presented at the center of the screen of a DAI microcomputer for $2 \mathrm{sec}$, followed by a blank interval of $500 \mathrm{msec}$. The words were $1 \mathrm{~cm}$ in height, printed in uppercase in green color on a black background. After the last item of the list, another rectangle printed in gray appeared at the top of the screen for $2 \mathrm{sec}$. This indicated the beginning of the recall period, which lasted $1 \mathrm{~min}$, during which subjects had to recall as many words of the list as possible, regardless of their order of presentation, and to write them down from top to bottom on a sheet provided. The subjects used one sheet per list and were also instructed to remain silent during the whole session, which lasted about $14 \mathrm{~min}$. The experimental design comprised two conditions, one in quiet at $37 \mathrm{~dB}(\mathrm{~A})$ and the other in background speech. This consisted of a continuous reading of an Arabic passage (from The Prophet, by G. K. Gibran) at an average level of $75 \mathrm{~dB}(\mathrm{~A})$, presented through two Lansing loudspeakers placed in front of the subject.

\section{Subjects}

Two independent groups of 12 female students from the introductory psychology course of the Université Louis-Pasteur of Strasbourg took part in the experiment. Their age varied between 19 and 22 years (mean: 20), and none was familiar with Arabic. None of the subjects had previously participated in a free recall experiment.

\section{Procedure}

Each subject performed the free recall task first in a silent pretest session; scores on this training phase were used to assign subjects to two matched groups. In the test session, one group of 12 subjects performed the task in quiet, while the other group was assigned to the speech condition. Testing occurred in the afternoon between 15:30 and 16:00; the subjects were tested individually and were paid for participating.

\section{RESULTS}

In the pretest session, the mean numbers of words recalled per list and per group were 8.08 and 8.33 , respectively. The analysis of variance showed no difference between groups $[F(1,22)<1]$ and a highly significant serial position effect $[F(15,330)=9.132, p<.005]$. This indicates that the two groups of subjects were comparable in performance prior to the experiment. The group $x$ serial position interaction was negligible $[F(15,330)<$ 1]. Results of the experimental conditions are presented in Figure 1. This illustrates the classical shape of the free recall curve, reflecting clear recency and primacy effects

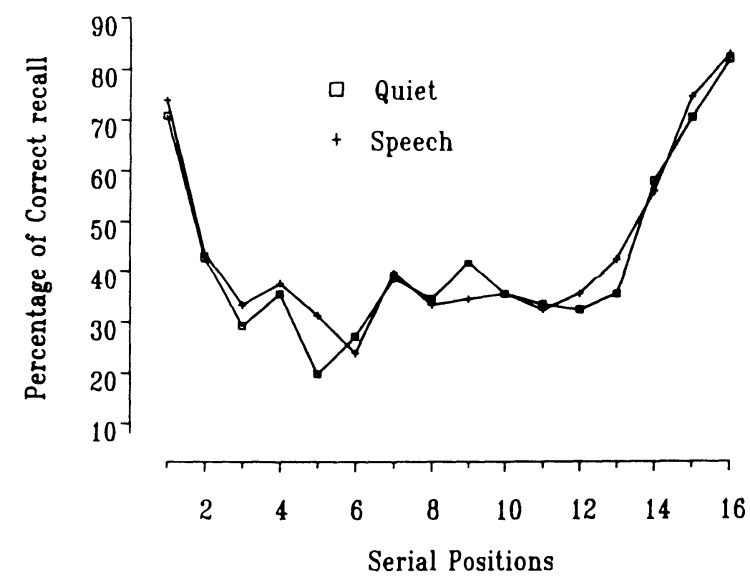

Figure 1. Mean number of words recalled, as a function of serial positions in quiet or in the presence of continuous irrelevant speech in immediate free recall.

together with poorer recall of the intermediate items. There is clearly no effect of irrelevant speech at any point in the serial position curve. This is confirmed by the analysis of variance, which showed no effect of condition $[F(1,22)<1]$, with a mean of 6.87 words recalled during quiet and 7.11 during speech. The serial position factor was highly significant $[F(15,330)=23.469, p<.001]$, but the interaction between conditions and serial position was negligible $[F(15,330)<1]$. In order to increase the power of the comparison, we ran an analysis of covariance, with the pretest data of each subject as covariate, all the subjects having performed the pretest session in silence. Again the analysis revealed no difference between conditions $[F(1,21)<1]$, a significant effect of serial position $[F(15,329)=18.77, p<.001]$, and no condition $X$ position interaction $[F(15,329)<1]$.

\section{DISCUSSION}

The results of this study are very clear-cut in showing not a trace of an effect of irrelevant speech on the immediate free recall of lists of 16 words. The shape of the serial position curve is classic, with marked evidence of both primacy and recency, neither of which appears to be at all influenced by the presentation of continuous irrelevant prose. Why should this be? Before going on to discuss potential theoretical implications, we should consider the possibility that we had simply failed to produce conditions under which irrelevant speech could affect performance. Fortunately, however, we can rule out this possibility, since our subjects also took part in a second experiment in which they attempted the immediate serial recall of sequences of nine visually presented digits under a range of conditions that included both quiet and the irrelevant speech condition used here. This experiment, which has been reported elsewhere (Salamé \& Baddeley, 1989, Experiment 3), showed a clear effect of irrelevant speech, which increased errors from $28 \%$ to $44 \%(p<.01)$.

The clear absence of an effect of irrelevant speech on the primacy component of free recall, along with the middle portion of the curve, suggests that irrelevant speech does not affect long-term learning. There is considerable evidence to indicate that this part of the serial position curve relies principally on semantic coding (Glanzer, 1972), and since there is no reason to assume that the irrelevant speech would interfere with the semantic encoding of the visually presented words, the absence of an effect of irrelevant speech is understandable. It is true that ar- 
ticulatory suppression may have a small but significant effect on this portion of a curve (Richardson \& Baddeley, 1975), but this probably reflects the utilization of subvocal rehearsal, a process that is often assumed to occur, particularly during early parts of the curve, and that is assumed to be disrupted by articulatory suppression.

The absence of an effect of irrelevant speech on recency might at first seem more puzzling. Certainly the earlier Atkinson and Shiffrin (1968) interpretation of recency as reflecting the output of a unitary short-term store, might predict that the irrelevant speech would corrupt the store and hence impair performance. However, as mentioned earlier, Baddeley and Hitch (1974) showed that even a concurrent digit load does not disrupt recency. The absence of an effect here is quite consistent with the assumption that recency reflects the operation of a retrieval strategy that can be applied to a number of stores, but does not necessarily reflect the output of the short-term phonological storage component of the articulatory loop. Our result therefore adds to the evidence against the view that both recency in free recall and digit span reflect a common system.

We should finally consider the practical implications of our result. If it implies that irrelevant speech does not impair long-term semantically based learning, then it suggests that noise pollution from unwanted speech may be considerably less problematic than might be suggested on the basis of the many earlier results that rely on immediate serial recall. It is of course entirely possible, however, that other factors, including, perhaps, the semantic content of the unattended material, may be important in determining what does interfere with long-term learning.

\section{REFERENCES}

Atkinson, R. C., \& Shiffrin, R. M. (1968). Human memory: A proposed system and its control processes. In K. W. Spence (Ed.), The psychology of learning and motivation: Advances in research and theory (Vol. 2, pp. 89-195). New York: Academic Press.

BADDELEY, A. D. (1986). Working memory. Oxford, England: Oxford University Press.

BADDELEY, A. D., \& Hitch, G. (1974). Working memory. In G. A. Bower (Ed.), Recent advances in learning and motivation (Vol. 8, pp. 47-90). New York: Academic Press.
Baddeley, A. D., \& Salamé, P. (1986). The unattended speech effect: Perception or memory? Journal of Experimental Psychology: Learning, Memory, \& Cognition, 12, 525-529.

Baddeley, A. D., Thomson, N., \& Buchanan, M. (1975). Word length and the structure of short-term memory. Journal of Verbal Learning \& Verbal Behavior, 14, 575-589.

Baddeley, A. D., \& Warrington, E. K. (1970). Amnesia and the distinction between long- and short-term memory. Journal of Verbal Learning \& Verbal Behavior, 9, 176-189.

COLle, H. A. (1980). Auditory encoding in visual short-term recall: Effects of noise intensity and spatial location. Journal of Verbal Learning \& Verbal Behavior, 19, 722-735.

Colle, H. A., \& Welsh, A. (1976). Acoustic masking in primary memory. Journal of Verbal Learning \& Verbal Behavior, 15, 17-32.

GlanZER, M. (1972). Storage mechanisms in recall. In G. H. Bower (Ed.), The psychology of learning and motivation: Advances in research and theory (Vol. 5, pp. 129-193). New York: Academic Press.

Juilland, A., Brodin, D., \& Davidovitch, C. (1970). Frequency dictionary of French words. The Hague: Mouton.

Richardson, J. T. E., \& Baddeley, A. D. (1975). The effect of articulatory suppression in free recall. Journal of Verbal Learning \& Verbal Behavior, 14, 623-629.

Salamé, P., \& Baddeley, A. D. (1982). Disruption of short-term memory by unattended speech: Implications for the structure of working memory. Journal of Verbal Learning \& Verbal Behavior, 21, 150-164.

Salamé, P., \& Baddeley, A. D. (1986). Phonological factors in STM: Similarity and the unattended speech effect. Bulletin of the Psychonomic Society, 24, 263-265.

Salamé, P., \& BADDELEY, A. D. (1987). Noise, unattended speech and short-term memory. Ergonomics, 30, 1185-1193.

SalAmÉ, P., \& BADDELEY, A. D. (1989). Effects of background music on phonological short-term memory. Quarterly Journal of Experimental Psychology, 41A, 107-122.

(Manuscript received April 7, 1990.) 